\title{
The catalase-peroxidase of Mycobacterium intracellulare: nucleotide sequence analysis and expression in Escherichia coli
}

\author{
Sheldon L. Morris, ${ }^{*}$ Jaygopal NaIR and David A. Rouse \\ Laboratory of Mycobacteria, Center for Biologics Evaluation and Research, Food and Drug Administration, \\ 8800 Rockville Pike, Bethesda, Maryland 20892, USA
}

(Received 17 February 1992; revised 14 July 1992; accepted 3 August 1992)

\begin{abstract}
The activation of catalase genes in response to oxidative stress may contribute to the intracellular survival of mycobacteria. In this report, the nucleotide sequence of a mycobacterial catalase gene is described. The deduced protein sequence of this Mycobacterium intracellulare gene (M185) was $60 \%$ identical to the Escherichia coli hydroperoxidase I (HPI) protein, 59\% identical to the Salmonella typhimurium (HPI) catalase, and $47 \%$ identical to a Bacillus stearothermophilus peroxidase. The MI85 protein, expressed in $E$. coli, has also been shown to have peroxidase and catalase activities. Furthermore, Southern blot hybridizations, which demonstrated that a MI85 gene probe hybridizes with chromosomal DNA from thirteen different strains of mycobacteria, suggest that this catalase-peroxidase gene is prevalent in the mycobacterial genus. The availability of catalase gene probes should permit an evaluation, at the molecular level, of the role of catalase in mycobacterial pathogenesis.
\end{abstract}

\section{Introduction}

One hundred years after the pioneering studies of Robert Koch on Mycobacterium tuberculosis, mycobacterial disease remains an enormous international public health problem. About 1.7 billion people, one-third of the world's population, are infected with Mycobacterium tuberculosis. Annually, three million deaths $-26 \%$ of preventable deaths worldwide - result from disease caused by $M$. tuberculosis (Kochi, 1991). Ten to fifteen million people suffer with leprosy, the complex chronic infectious disease caused by $M$. leprae (Bloom \& Godal, 1983). More than $25 \%$ of patients with acquired immunodeficency syndrome (AIDS) in the United States develop $M$. avium, $M$. intracellulare complex (MAC) disease (Horsbaugh, 1991). MAC bacilli are the most common bacterial isolate and the most frequent cause of systemic bacterial infections in American AIDS patients (Young, 1988).

Efforts to improve diagnosis and treatment of mycobacterial diseases have been impeded by a lack of progress in understanding the mechanisms of mycobacterial pathogenesis and factors which contribute to the

* Author for correspondence. Tel. (301) 496 5517; fax (301) 4022776.

The nucleotide sequence data reported in this paper have been submitted to GenBank and have been assigned the accession number M86741 virulence of mycobacteria. Since mycobacteria proliferate inside macrophages, it has been speculated that catalases may protect acid-fast bacilli from the deleterious effects of peroxide and, therefore, may play a crucial role in the in vivo survival of mycobacteria. The virulence of two other intracellular pathogens, Nocardia asteroides and Leishmania donovani, has been related to their catalase content (Beaman \& Beaman, 1984). Catalases probably enhance the pathogenicity of these microorganisms by metabolizing hydrogen peroxide, a toxic oxygen metabolite which is released by phagocytes in response to bacterial challenge. There is extensive evidence which suggests that peroxide and its associated toxic oxygen metabolites are responsible, in part, for the anti-mycobacterial activity of macrophages (Jackett $\boldsymbol{e t}$ $a l$. 1981 $a, b$; Lowrie, 1983). The most direct evidence implicating catalases as mycobacterial virulence factors is derived from studies demonstrating the protective effect of exogenous catalase. In these experiments, exogenous catalase protected against the killing of $M$. microti by lymphokine-activated murine macrophages (Walker \& Lowrie, 1981). More recent studies have shown, however, that the resistance of $M$. intracellulare strains to peroxide does not correlate with their catalase content and that the susceptibility of $M$. tuberculosis to killing by activated macrophages is not related to peroxide susceptibility (Gangadharam \& Pratt, 1984; O'Brien et al., 1991). The role of catalase in mycobac- 
terial virulence, therefore, may be very complex and has not been clearly delineated.

In this report, we describe the initial cloning, nucleotide sequence analysis, and expression of a mycobacterial gene encoding a catalase-peroxidase. We also demonstrate that this gene encodes a protein which is $60 \%$ identical to the $E$. coli hydroperoxidase I (HPI) enzyme. Finally, we discuss how molecular studies with catalase gene probes may clarify the role of catalases in mycobacterial pathogenesis.

\section{Methods}

Cloning and nucleotide sequence analysis of the MI85 gene. The identification and isolation of the bacteriophage from a $M$. intracellulare $\lambda \mathrm{gt} 11$ gene expression library which expresses the MI85 protein has been previously described (Morris et al., 1988). Recombinant bacteriophage DNA was isolated using the LambdaSorb reagent (Promega) and protocols provided by the manufacturer. The $4.8 \mathrm{~kb}$ mycobacterial DNA insert was removed from the bacteriophage by digestion with EcoRI and passage through a low-melting-point agarose gel. This insert was then cloned into the pGEMEX vector (Promega). Deletions of the insert fragment were prepared in the pGEMEX vector using exonuclease gene deletion protocols. The pGEMEX recombinants containing the deleted gene fragments were subsequently expressed as gene 10 fusion proteins. The sizes of the resultant fusion proteins were evaluated using SDS-PAGE. Plasmids containing fragments greater than $2.3 \mathrm{~kb}$ expressed nearly full-length fusion proteins, indicating that most of the protein coding sequence was located within a $2.3 \mathrm{~kb} E c o \mathrm{RI} / S m a \mathrm{I}$ restriction fragment. This $2.3 \mathrm{~kb}$ fragment was then cloned into the Bluescript KS vector (Stratagene). To facilitate nucleotide sequence analysis, plasmids containing deletions of the EcoRI/SmaI fragment were generated by exonuclease III digestions. Dideoxynucleotide sequence analysis was performed by Lark Sequencing (Houston) and by our laboratory using Bst I polymerase protocols (Bio-Rad Laboratories). Because the EcoRI/ SmaI fragment did not include DNA encoding the amino terminus of the MI85 protein, overlapping clones were identified using nucleic acid hybridizations. A $338 \mathrm{bp} \mathrm{EcoRI/SphI} \mathrm{fragment} \mathrm{from} \mathrm{the} \mathrm{5'} \mathrm{region} \mathrm{of} \mathrm{the}$ $2.3 \mathrm{~kb}$ fragment was nick-translated (Bethesda Research Laboratories) with $\alpha^{-32}$ P-dCTP (NEN/DuPont) and served as the probe for screening the $M$. intracellulare library. Plaque hybridizations were performed using standard protocols (Sambrook et al., 1989). EcoRI insert fragments from hybridization-positive clones were cloned into Bluescript vectors. The nucleotide sequencing of the gene was then completed using primers designed from the $5^{\prime}$ end of the $2.3 \mathrm{~kb}$ fragment.

Expression of the MI85 protein and characterization of the peroxidase and catalase enzymic activities. The isolation and characterization of $\lambda \mathrm{gt} 11$ bacteriophages expressing recombinant nontuberculous mycobacterial antigens has been reported (Morris et al., 1988, 1990; Rouse et al., 1991). DNA insert fragments from recombinant bacteriophages expressing MI22, MK35, and MI85 mycobacterial antigens were cloned into the pGEMEX vector system (Promega) and then transformed into the $E$. coli strain BL21 ( $p L y s S)$. As a control, the pGEMEX plasmid, which expresses only the T7 gene 10 protein, was also transformed into the same $E$. coli host. Expression of the gene 10 fusion proteins and the wild-type gene 10 protein was performed as described by the manufacturer. The level and integrity of expression was evaluated by SDS-PAGE and by immunoblot analyses using specific monoclonal antibodies and absorbed hyperimmune anti- $M$. intracellulare burro sera.

The peroxidase activity of $10 \mu \mathrm{g}$ of each cell lysate was evaluated by assaying for the metabolism of the peroxidase substrates [2,2'-azino bis(2-ethylbenzthiazoline 6-sulphonic acid)] (ABTS) and $o$-dianisidine, using protocols provided by the manufacturer (Sigma). Both substrates produce soluble end products that can be measured as $A_{405}$. The catalase activity of the cell lysates was determined by the method of Beers \& Sizer (1952), which monitors the decomposition of hydrogen peroxide as $A_{240}$.

Southern blot hybridizations using MI85 gene probes. The following mycobacterial strains were obtained from the American Type Culture Collection (Rockville, MD): M. asiaticum (25274), M. avium (35714), $M$. bovis BCG (27291), M. bovis (35720), M. fortuitum (6841), $M$. intracellulare (13950), M. kansasii (12480), M. phlei (11758), M. scrofulaceum (19981), $M$. smegmatis (14468), $M$. terrae (15755), $M$. tuberculosis H37Ra (25177), and M. tuberculosis H37Rv (27294). These strains were grown in Long's synthetic medium (with $1 \%$ glucose, w/v) until mid-exponential phase. Total DNA was isolated as described previously (Rouse et al., 1991).

Approximately $3 \mu \mathrm{g}$ of each preparation of total DNA was digested with $E c o$ RI for $2-3 \mathrm{~h}$ precipitated with ethanol, separated on a $1 \%$ $(w / v)$ agarose gel, and transferred to nylon membranes by standard procedures. The original $4.8 \mathrm{~kb}$ insert cloned into pGEMEX $(1 \mu \mathrm{g})$ was biotinylated with the BioNick Labelling System as described by the manufacturer (Bethesda Research Laboratories). The Southern blot was hybridized to this probe using reagents and protocols provided in the PHOTOGENE Detection System (BRL). After hybridization at $42{ }^{\circ} \mathrm{C}$ for $18 \mathrm{~h}$, the Southern blot was washed twice, 5 min per wash, in $5 \times \mathrm{SSC} / 0.5 \% \mathrm{SDS}$ at $65^{\circ} \mathrm{C}$ and then twice, $20 \mathrm{~min}$ per wash, in $0.1 \times \mathrm{SSC} / 1.0 \% \mathrm{SDS}$ at $52{ }^{\circ} \mathrm{C}$. The membrane was washed for $5 \mathrm{~min}$ in $2 \times$ SSC followed by a brief wash in TBS [100 mM-Tris (pH 7.4), $150 \mathrm{~mm}-\mathrm{NaCl}$ s supplemented with $0.05 \%$ Tween 20 (TTBS). After blocking with $3 \%(\mathrm{w} / \mathrm{v})$ bovine serum albumin (Sigma) in TTBS at $65^{\circ} \mathrm{C}$ for $1 \mathrm{~h}$, the blot was incubated with streptavidin-alkaline phosphatase conjugate for $10 \mathrm{~min}$ at room temperature, and washed twice with TTBS (15 min per wash). A final wash for $1 \mathrm{~h}$ at room temperature was performed using a solution provided by the manufacturer. The membrane was then air-dried and incubated with the detection reagent for $3.5 \mathrm{~h}$. Kodak XAR-2 film was exposed to the Southern blot for $10 \mathrm{~min}$ and then developed.

\section{Results}

\section{Nucleotide sequence analysis of the MI85 gene}

The isolation and characterization of a recombinant bacteriophage from a $M$. intracellulare $\lambda \mathrm{gtl1}$ gene expression library which expresses a recombinant fusion protein derived from a $85 \mathrm{kDa}$ mycobacterial antigen (MI85) has been previously described (Morris et al., 1988). Restriction digestions and gene deletion analyses indicated that most of the MI85 coding sequence was encoded by a $2.3 \mathrm{~kb} E c o \mathrm{RI} / S m a \mathrm{I}$ fragment within the original $4.8 \mathrm{~kb}$ mycobacterial DNA insert fragment. The subcloning of this $2.3 \mathrm{~kb}$ fragment, the identification of overlapping $\lambda \mathrm{gt} 11$ bacteriophages with nucleic acid hybridization procedures, and the sequencing protocols are described in Methods. The complete nucleotide sequencing strategy is summarized in Fig. 1. 


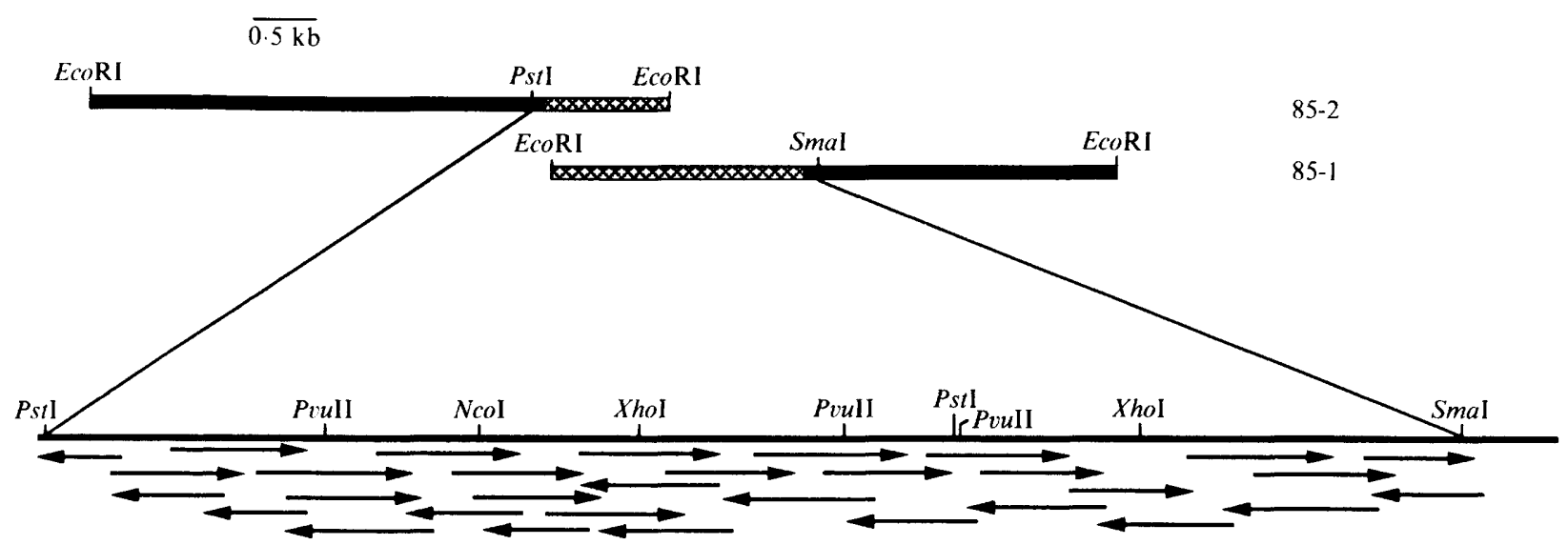

Fig. 1. Sequencing strategy for the MI 85 gene. The orientation of the overlapping insert fragments from $\lambda$ gt 11 bacteriophages $85-1$ and 85-2 is shown at the top. Hatched boxes designate the coding sequence of the MI85 protein. Below is the nucleotide sequencing strategy. The chromosomal sequence from the PstI site (85-2) to the $S m a I$ site (85-1) was sequenced as described in Methods. The arrows indicate the direction and extent of elongation in the sequencing reactions.

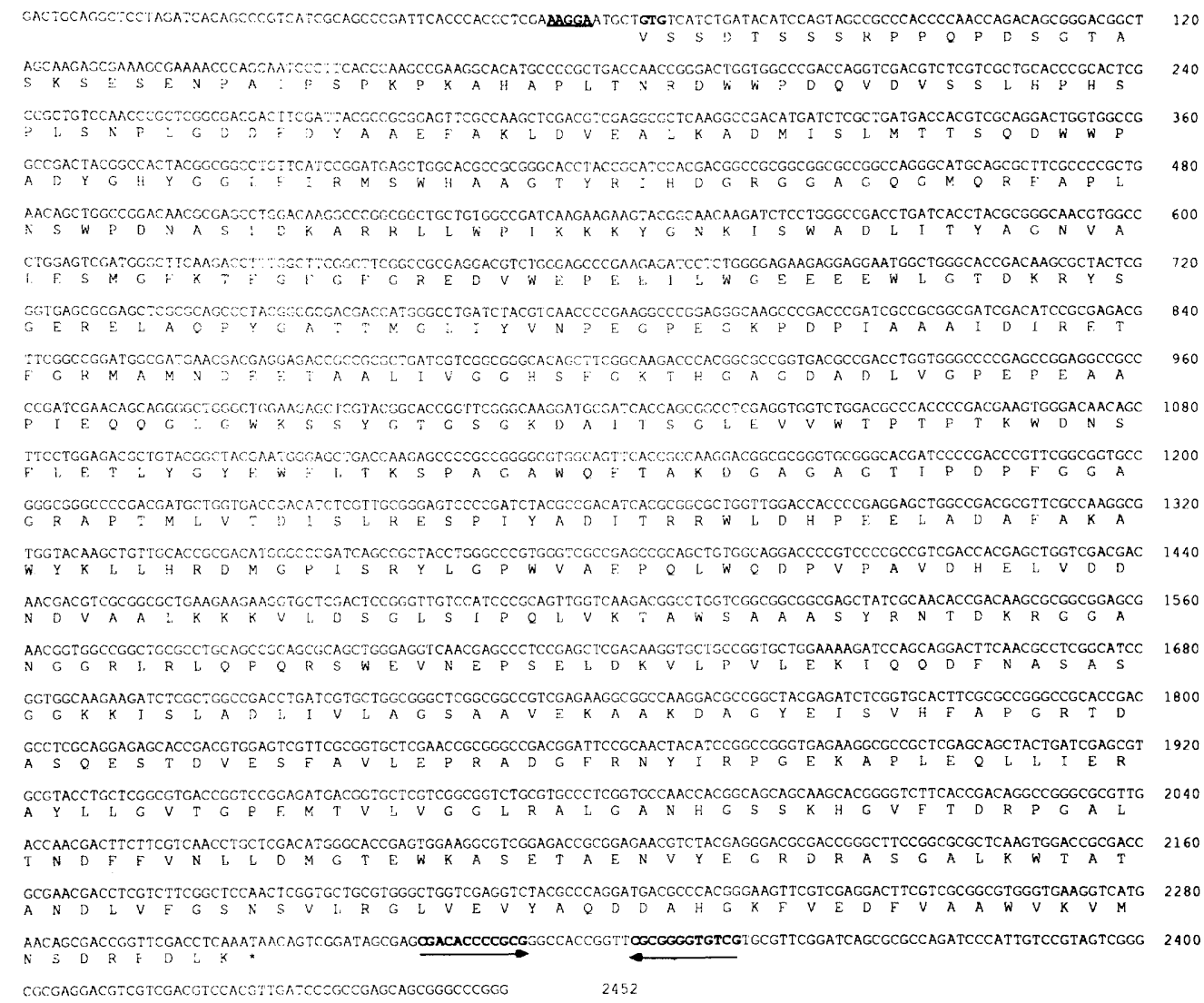

Fig. 2. Sequence of a $2452 \mathrm{bp}$ fragment from the $M$. intracellulare genome containing the MI85 gene. The ORF commences at base 66 and terminates at 2304 . The predicted amino acid sequence is indicated below the DNA sequence. A potential ribosome binding site, $5 \mathrm{bp}$ upstream of the ORF, is underlined. The arrows designate an inverted repeat sequence 15 bp downstream of the termination codon.

The nucleotide sequence and the deduced protein sequence of MI85 are shown in Fig. 2. A 2238 bp open reading frame (ORF) initiating at GTG (base pair 66) and terminating at TAA (base pair 2306) was identified within this sequence. The ORF predicts a 745 amino acid residue protein with a molecular mass of $83.5 \mathrm{kDa}$. This 
molecular mass is consistent with our initial immunoblot size estimations. Five base pairs upstream from the initiation codon is a putative Shine-Dalgarno site, the ribosomal binding sequence AAGGA (Gold et al., 1981). A potential rho-independent termination sequence containing a 12 bp hyphenated dyad was found 15 base pairs downstream from the termination codon. Inverted repeat sequences have been identified downstream from several genes encoding mycobacterial proteins and may be a general mechanism for transcriptional termination in mycobacteria (Shinnick et al., 1989; Collins et al., 1990; Nair et al., 1992). The $70 \% \mathrm{G}+\mathrm{C}$ content of the MI85 gene is consistent with the high percentage of $\mathrm{G}+\mathrm{C}$ base pairs found in genomic DNA from all mycobacterial species. The $\mathrm{G}+\mathrm{C}$ content increases to $94 \%$ in the third base pair of the amino acid codons. Similar elevated $\mathrm{G}+\mathrm{C}$ ratios at the third codon base position have been reported for other mycobacterial genes (Shinnick, 1987; Matsuo et al., 1988; Nair et al., 1992).

\section{The MI85 gene encodes a mycobacterial catalase- peroxidase}

Computer-aided comparisons (Devereux et al., 1984) of the MI85 nucleic acid and deduced amino acid sequences revealed that MI85 encodes a mycobacterial catalaseperoxidase. As seen in Fig. 3, the deduced MI85 protein sequence is $60 \%$ identical and $72 \%$ similar (identical and conserved amino acid residues) to the $E$. coli peroxidasecatalase HPI (Triggs-Raine et al., 1988). Furthermore, the deduced $M$. intracellulare protein sequence is $59 \%$ identical and $71 \%$ similar to a Salmonella typhimurium hydroperoxidase I (Loewen \& Stauffer, 1990) and $47 \%$ identical and $62 \%$ similar to a peroxidase from Bacillus stearothermophilus (Loprasert et al., 1989). In highly conserved regions of the protein, the sequence identity exceeds $75 \%$. The region from Trp95 to Pro199 of MI85 is $82 \%$ and $81 \%$ identical to the corresponding residues of the respective $E$. coli HPI enzyme and the $S$. typhimurium catalase. The carboxyl terminal portion of the MI85 protein from Asp701 to Leu746 is $83 \%$ identical to the $E$. coli HPI protein, $85 \%$ identical to the $S$. typhimurium protein, and $75 \%$ identical to the $B$. stearothermophilus peroxidase-catalase.

\section{Southern blot hybridizations with MI85 gene probes}

To evaluate the prevalence of this catalase gene within the mycobacterial genus, a nucleic acid probe constructed from the original $4.8 \mathrm{~kb}$ insert fragment containing the MI85 coding sequence was hybridized to EcoRIdigested DNA extracted from thirteen different strains of mycobacteria. As seen in Fig. 4, the MI85 gene probe

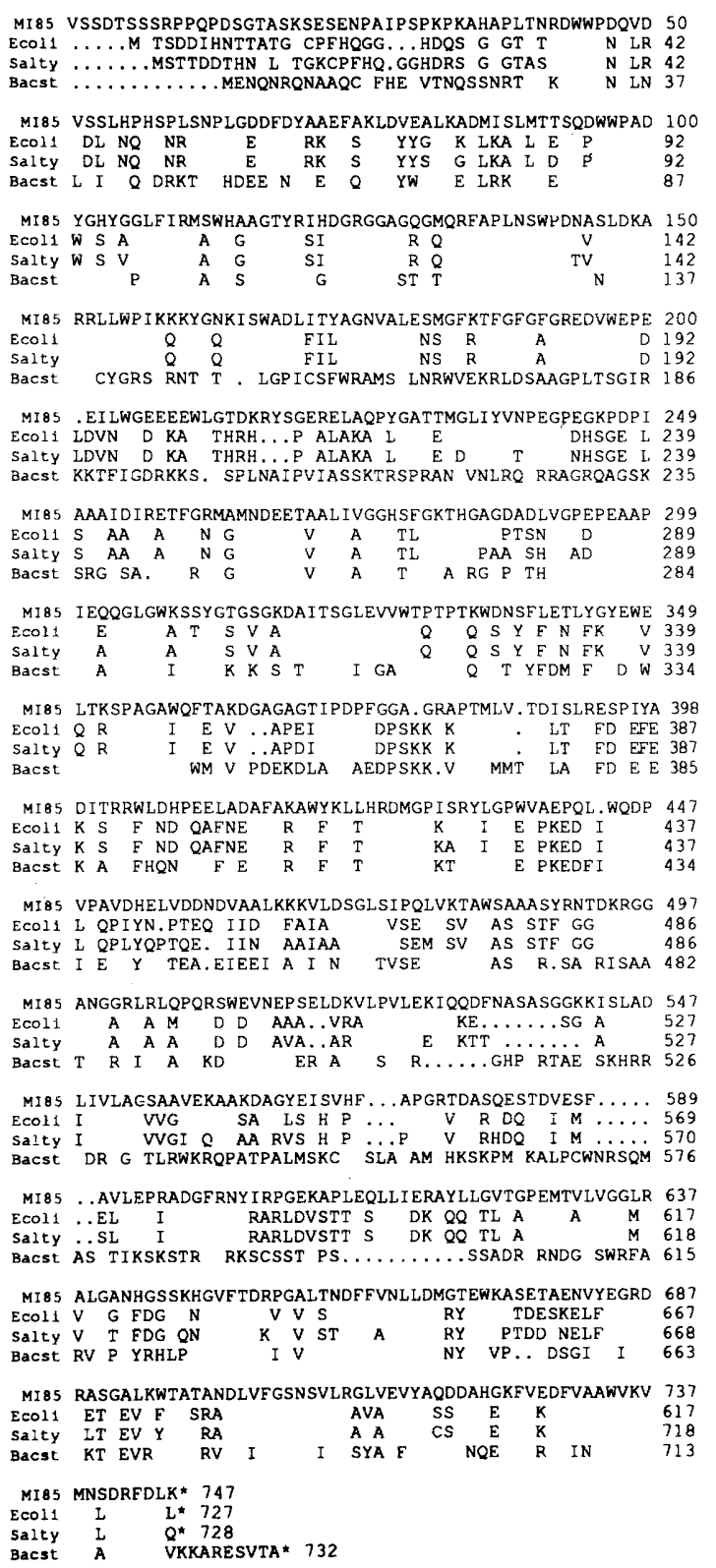

Fig. 3. Comparison of the predicted amino acid sequence of the MI85 protein with the sequences of $E$. coli (Ecoli), S. typhimurium (Salty) and $B$. stearothermophilus (Bacst) peroxidase-catalases. The differences in the peroxidase protein sequences can be identified by the substitution of another amino acid below the MI85 sequence. Regions of protein sequence identity are designated by blank spaces. Dots represent amino acid residues that are not present within a specific predicted protein sequence.

hybridized to genomic DNA from all species of mycobacteria tested. Subsequent experiments using an amino terminus $840 \mathrm{bp} E c o \mathrm{RI} / \mathrm{NcoI}$ probe and with a $2.3 \mathrm{~kb} E c o \mathrm{RI} / S m a I$ probe have shown identical hybridization patterns. Although the banding patterns differ among several of the strains, the MI85 gene probe reacts 


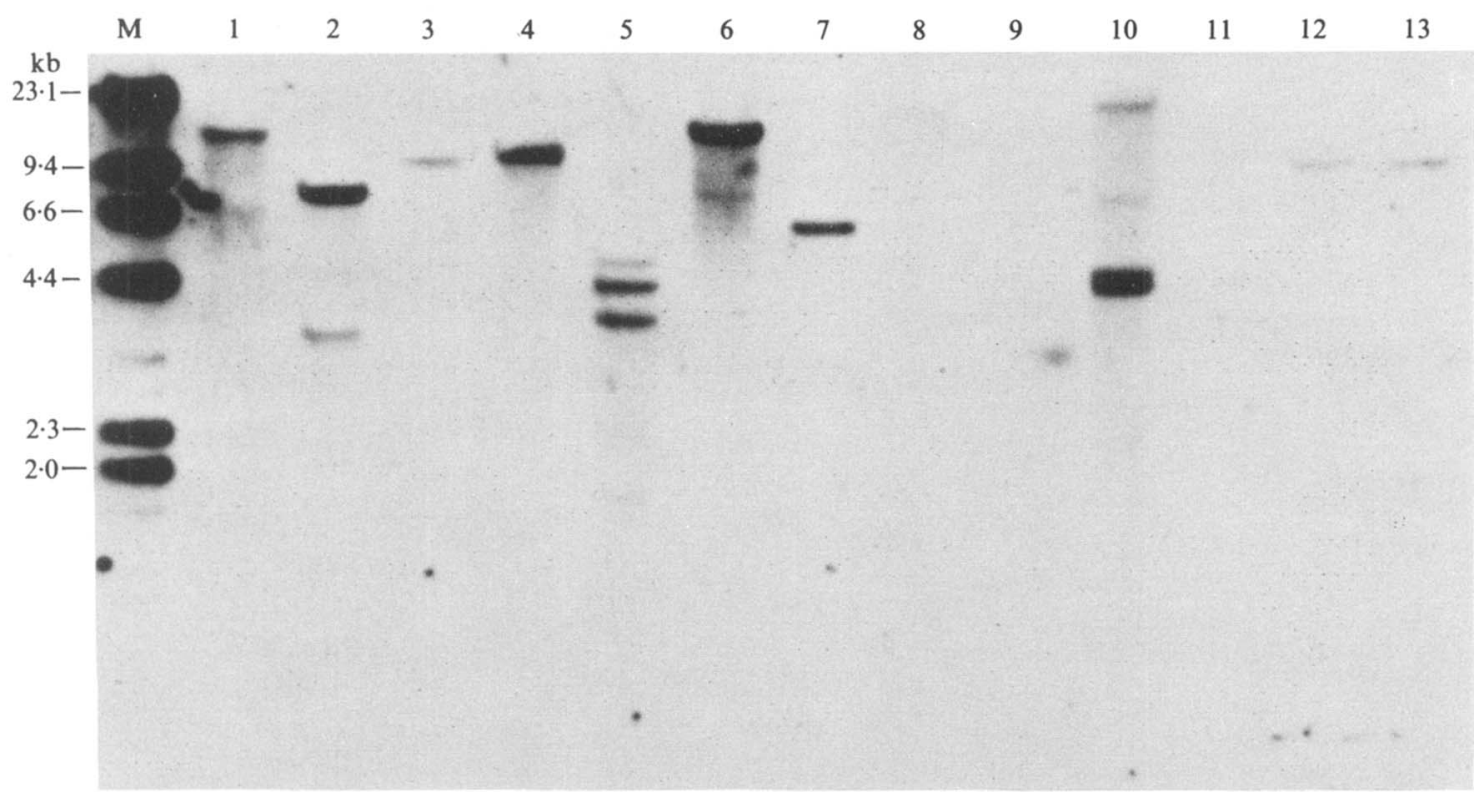

Fig. 4. Non-radioactive Southern blot hybridization of EcoRI-digested mycobacterial total DNA against MI85 gene probe. The PhotoGene chemiluminescence hybridization protocols are described in Methods. Mycobacterial DNA was applied to the following lanes: $1, M$. asiaticum $; 2, M$. avium $; 3, M$. bovis BCG; $4, M$. bovis $; 5, M$. fortuitum $; 6, M$. intracellulare $; 7, M$. kansasii $; 8, M$. phlei $; 9, M$. scrofulaceum; 10, M. smegmatis; 11, M. terrae; 12, M. tuberculosis H37Ra, and 13, M. tuberculosis H37Rv. Lane M contains biotinylated lambda/HindIII DNA molecular mass markers.

with $M$. asiaticum, $M$. avium, $M$. bovis, $M$. bovis BCG, $M$. fortuitum, M. kansasii, M. smegmatis, M. tuberculosis H37Ra, M. tuberculosis H37Rv, and to homologous $M$. intracellulare DNA. The hybridization of the MI85 probe to $M$. phlei, M. scrofulaceum, and $M$. terrae DNA is weak but readily apparent after longer exposures (data not shown).

\section{Expression of the MI85 catalase-peroxidase in E. coli}

To evaluate the enzymic activity of the MI85 recombinant proteins, lysates containing the MI85-gene 10 fusion constructs were assayed for peroxidase and catalase activity. Similar assays were done with control lysates containing overexpressed gene 10 protein and two other mycobacterial antigens expressed in $E$. coli - the MI22gene 10 fusion protein and the MK35-gene 10 fusion protein. The MI22 gene encodes the $M$. intracellulare homologue of the $M$. tuberculosis $19 \mathrm{kDa}$ antigen (Nair et al., 1992) and the MK 35 gene encodes an antigen derived from a $27 \mathrm{kDa}$ M. kansasii protein (S. Morris, unpublished data). Coomassie-blue-stained SDS-PAGE separations of these lysates are shown in Fig. 5(a). The apparent molecular masses for the fusion proteins (as determined by SDS-PAGE) are $107 \mathrm{kDa}$ for MI85-gene $10,60 \mathrm{kDa}$ for MK35-gene 10, and $45 \mathrm{kDa}$ for MI22gene 10. It is apparent that the relative amounts of fusion proteins in each of these lysates is nearly identical. Two common peroxidase substrates, $o$-dianisidine and ABTS, were chosen to evaluate the peroxidase activity in each of these lysates. The lysates containing the MI85-gene 10 fusion protein were significantly active against both $o$ dianisidine and ABTS (Fig. $5 b, c)$. In contrast, none of the control lysates metabolize these peroxidase substrates. The capacity of these lysates to utilize hydrogen peroxide as a substrate was evaluated using the catalase assay developed by Beers and Sizer (1952). This method assays the decomposition of peroxide in a phosphate buffer solution by measuring decreases in $A_{240}$. Catalatic activity was detected in only the MI85 and MK 35 lysates (Fig. $5 d$ ). Moreover, the MI85 lysate showed a greater capacity to metabolize hydrogen peroxide [30 units ( $\mathrm{mg}$ total protein $)^{-1}$ ] than MK35 [9 units (mg total protein) $\left.{ }^{-1}\right]$ during this time period.

\section{Discussion}

The immunopathogenic mechanisms of mycobacteria are not well understood, and mycobacterial virulence has not been clearly defined. Because mycobacteria are intracellular parasites which proliferate in an environment with high concentrations of toxic oxygen molecules, it has been suggested that catalases may play a role 


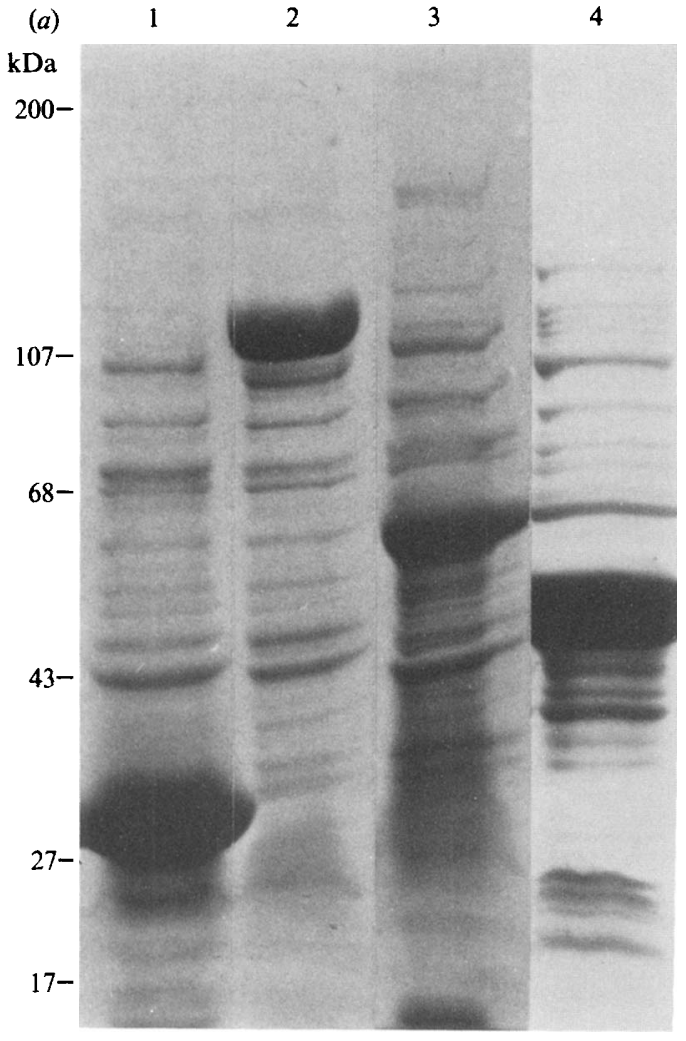

Fig. 5. Demonstration of peroxidase and catalase enzyme activities in a cell lysate containing an overexpressed MI85-gene 10 recombinant fusion protein. (a) SDS-PAGE and Coomassie blue staining of cell lysates containing overexpressed mycobacterial gene 10 fusion proteins. Lysates containing overexpressed gene 10 (lane 1), MI85 gene 10 (lane 2), MK 35 gene 10 (lane 3), and MI22 gene 10 (lane 4) were applied to the gel. $(b, c)$ Assays of the peroxidase activities of cell lysates containing the MI85 $(\square)$, MI22 ( $\square)$, and MK35 $(\diamond)$ gene 10 fusion proteins and the gene 10 control $(\odot)$, using ABTS $(b)$ and $o$-dianisidine (c) as substrates. Peroxidase activity was measured as changes in $A_{405}$ as described in Methods. (d) Assays of the catalatic activity of the recombinant gene 10 cell lysates. Catalatic activity was evaluated by measuring the decomposition of hydrogen peroxide as described in Methods. The results are plotted as a percentage of control $A_{240}$ values. Symbols as Fig. 5(b).

in the intracellular survival of these acid-fast bacilli (Jackett et al. 1981a, b; Walker \& Lowrie, 1981). However, more recent experiments examining the importance of mycobacterial catalases have yielded conflicting results (Gangadharam \& Pratt, 1984; O'Brien et al., 1991). We have initiated genetic studies aimed at better defining the role of catalase in mycobacterial virulence. The nucleotide sequence of a mycobacterial catalase-peroxidase has been obtained, and active mycobacterial catalase expressed in E. coli. The deduced $M$. intracellulare catalase protein sequence is $60 \%$ identical to the $E$. coli HPI enzyme (Triggs-Raine et al., 1988 ), $59 \%$ identical to the $S$. typhimurium HPI catalase
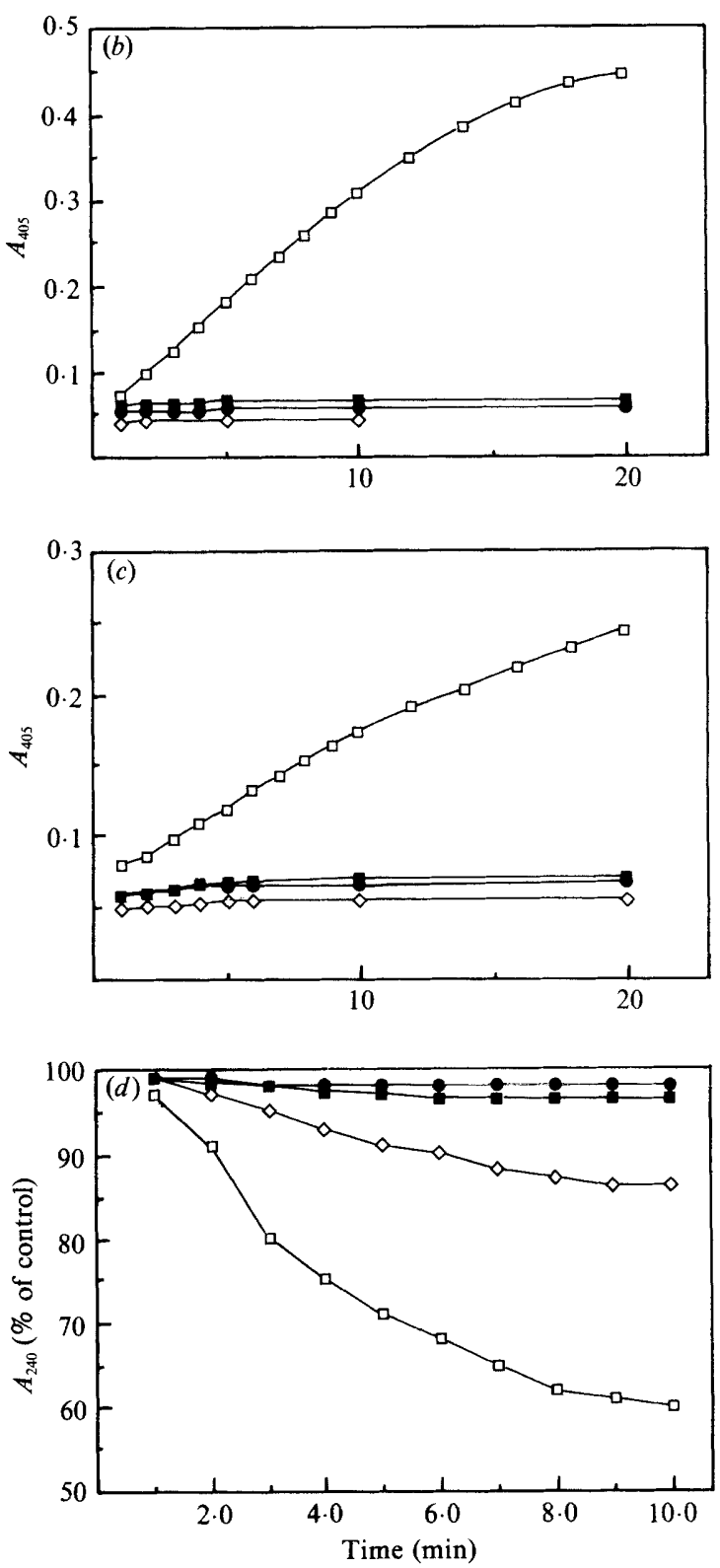

(Loewen \& Stauffer, 1990), and $47 \%$ identical to a $B$. stearothermophilus peroxidase-catalase (Loprasert et al., 1989).

Two catalases have been extensively characterized in E. coli. HPI (encoded by $k a t G$ ) is a prokaryotic broadspectrum bifunctional peroxidase-catalase inducible by hydrogen peroxide (Loewen et al., 1985). The E. coli catalase HPII (encoded by katE) is a monofunctional enzyme that has sequence similarities to eukaryotic catalases (von Ossowski et al., 1991). Biochemical and serological characterizations of mycobacterial lysates have also identified two mycobacterial catalases (Wayne \& Diaz, 1982). The mycobacterial T catalases, which 
have been identified in most mycobacterial species, have substrate specificities similar to the $E$. coli HPI peroxidase-catalases. The mycobacterial $\mathbf{M}$ catalase is a monofunctional HPII-like catalase which has a limited distribution within the mycobacterial genus. The broadspectrum substrate specificity of the overexpressed MI85 fusion protein suggests that we have cloned and expressed the gene encoding the $M$. intracellulare $\mathrm{T}$ catalase-peroxidase. Our Southern blot hybridization results are consistent with this prediction, since a MI85 gene probe hybridizes to total DNA isolated from all strains of mycobacteria that we have tested. Our nucleotide sequence analysis predicts that MI85 has $84 \mathrm{kDa}$ subunits. However, the molecular mass of the native $M$. intracellulare $\mathrm{T}$ catalase has been estimated to be $335 \mathrm{kDa}$ (Gruft \& Gaafar, 1974). These results suggest that the $M$. intracellulare $\mathrm{T}$ catalase is probably a tetramer, like the $E$. coli HPI enzyme. In contrast, the native molecular mass of the $M$. tuberculosis catalase has been estimated to be $160 \mathrm{kDa}$ (Diaz \& Wayne, 1974). Therefore, the analogous $M$. tuberculosis protein may be a dimer, similar to the $B$. stearothermophilus peroxidasecatalase. Experiments designed to clone, sequence and characterize the gene encoding the homologous $M$. tuberculosis catalase-peroxidase are currently in progress.

The identification of the gene encoding a mycobacterial $\mathrm{T}$ catalase-peroxidase provides a probe to study, at the molecular level, the function of this catalase in mycobacterial pathogenesis. The availability of this gene probe and new methods for isolating mRNA from mycobacteria should permit evaluation of the transcription activation of catalase genes in response to oxidative stress (Patel et al., 1991). Cloning and expression of this gene in $E$. coli should enable biochemical characterization of protein structure and function. Of particular importance, the development of new systems for cloning and expression in mycobacteria should permit gene replacement and substitution experiments with the catalase gene in mycobacteria (Stover et al., 1991). Studies assessing the relative virulence of recombinant mycobacteria having mutated or substituted catalase genes may elucidate the importance of catalase in mycobacterial pathogenesis. Furthermore, the catalase gene may be a useful probe for examining gene regulation in mycobacteria. The expression of the E. coli and Salmonella HPI peroxidase-catalases and at least seven other proteins, in response to oxidative stress, is mediated by the oxyR gene. (Christman et al., 1985; Greenberg \& Demple, 1989). A comparison of the sequences upstream from the putative MI85 initiation codon shows similarity to the putative binding domain of the oxyR trans-activating protein in the katG gene of $E$. coli (Tartagila et al., 1989). Experiments are in progress to examine the presence and function of an $\operatorname{oxy} R$-like regulon in mycobacteria and to ascertain the importance of $\operatorname{oxy} R$-regulated proteins in mycobacterial virulence. Finally, resistance to isoniazid, the primary drug used in the treatment of tuberculosis, often correlates with loss of catalase-peroxidase activity (Gangadharam, 1984). A catalase gene probe should allow a genetic examination of the association between catalase activity and isoniazid resistance in drug-resistant $M$. tuberculosis strains.

Note added in proof. The cloning of the M. tuberculosis catalase-peroxidase and the role of this enzyme in isoniazid resistance has recently been described (Zhang et al., 1992).

\section{References}

Beaman, L. \& Beaman, B. L. (1984). The role of oxygen and its derivatives in microbial pathogenesis and host defense. Annual Review of Microbiology 38, 127-148.

BEERS, R. F. \& SIZER, I. W. (1952). A spectrophotometric method for measuring the breakdown of hydrogen peroxide by catalase. Journal of Biological Chemistry 195, 133-140.

BloOM, B. R. \& Godal, T. (1983). Selective primary stategies for control of disease in the developing world. Reviews of Infectious Diseases 5, 765 .

Christman, M. F., Morgan, R. W., Jacobson, F. S. \& Ames, B. N. (1985). Positive control of a regulon for defenses against oxidative stress and some heat shock proteins in Salmonella typhimurium. Cell 41, 753-762.

Collins, M. E., Patki, A., Wall, S., Nolan, S. A., Goodjer, J., Woodward, M. J. \& DaLE, J. W. (1990). Cloning and characterization of the gene for the ' $19 \mathrm{kDa}$ ' antigen of Mycobacterium bovis. Journal of General Microbiology 136, 1429-1436.

DevereuX, J., Haerberli, P. \& Smithies, O. (1984). A comprehensive set of sequence analysis programs for VAX. Nucleic Acids Research 12, 387-395.

DiAZ, G. A., \& WAYNE, L. G. (1974). Isolation and characterization of catalase produced by Mycobacterium tuberculosis. American Review of Respiratory Disease 110, 312-319.

GANGADHRAM, P. R. J. (1984). Drug resistance in mycobacteria. Boca Raton: CRC Press, Inc.

Gangadharam, P. R. J. \& Pratt, P. K. (1984). Susceptibility of Mycobacterium intracellulare to hydrogen peroxide. American Review of Respiratory Disease 130, 309-311.

Gold, L., Pribnow, D., SChneider, T., Shinedling, S., Singer, B. \& STORMO, G. (1981). Translational initiation in prokaryotes. Annual Review of Microbiology 35, 365-403.

GreenberG, J. T. \& DEMPLE, B. (1989). A global response induced in Escherichia coli by redox-cycling agents overlaps with that induced by peroxide stress. Journal of Bacteriology 171, 3933-3939.

Gruft, H. \& GAAFAR, H. A. (1974). Multiple catalases of mycobacteria: differences in molecular weight. American Review of Respiratory Disease 110, 320-323.

HoRSBAUGH, C. R. (1991). Mycobacterium avium complex infection in the Acquired Immunodeficiency Syndrome. New England Journal of Medicine 324, 1332-1338.

JACKeTt, P. S., ABER, V. R., Mitchison, R. D. A. \& Lowrie, D. B. $(1981 a)$. The contribution of hydrogen peroxide resistance to the virulence of Mycobacterium tuberculosis during the first six days after intravenous infection of normal and BCG-vaccinated guinea pigs. British Journal of Experimental Pathology 62, 34-40.

J ACKeTt, P. S., ANDREW, P. W., Aber, V. R. \& LoWrie, D. B. (1981 b). Hydrogen peroxide and superoxide release by alveolar macrophages from normal and BCG-vaccinated guinea pigs after intravenous challenge with Mycobacterium tuberculosis. British Journal of Experimental Pathology 62, 419-428.

KoCHI, A. (1991). The global tuberculosis situation and the new contiol strategy of the world health organization. Tubercle 72, 1-6. 
LOEWEN, P. C. \& StaufFer, G. V. (1990). Nucleotide sequence of $k a t ~ G$ of Salmonella typhimurium LT2 and characterization of its product, hydroperoxidase I. Molecular and General Genetics 224, 147-151.

Loewen, P. C., Swatala, J. \& Triggs-Raine, B. L. (1985). Catalase HPI and HPII in Escherichia coli are induced independently. Archives of Biochemistry and Biophysics 243, 144-149.

Loprasert, S., Negro, S. \& OKaDA, H. (1989). Cloning, nucleotide sequence and expression in Escherichia coli of Bacillus stearothermophilus peroxidase gene (perA). Journal of Bacteriology 171, 4871-4875.

LowRIE, D. B. (1983). The macrophage and mycobacterial infections. Transactions of the Royal Society of Tropical Medicine 77, 646-655.

Matsuo, K., Yamaguchi, R., Yamazaki, R. A., Tasaka, H. \& YAMADA, T. (1988). Cloning and expression of the Mycobacterium bovis BCG gene for extracellular $\alpha$ antigen. Journal of Bacteriology 170, 3847-3854.

Morris, S. L., Rouse, D. A., Hussong, D. \& Chaparas, S. D. (1988). Isolation and characterization of a recombinant $\lambda$ gt 11 bacteriophage which expresses an immunoreactive Mycobacterium intracellulare protein in Escherichia coli. Infection and Immunity 56, 3026-3031.

Morris, S. L., Rouse, D. A., Hussong, D. \& Chaparas, S. D. (1990). Isolation and characterization of recombinant $\lambda \mathrm{gtl} 1 \mathrm{bacteriophages}$ expressing four different Mycobacterium intracellulare antigens. Infection and Immunity 58, 17-20.

NaIR, J., RouSE, D. A. \& MorRIS, S. L. (1992). Nucleotide sequence analysis and serologic characterization of the Mycobacterium intracellulare homologue of the Mycobacterium tuberculosis $19 \mathrm{kDa}$ antigen. Molecular Microbiology 6, 1431-1439.

O'Brien, S., JACKeTt, P. S., LoWrie, D. B. \& ANDREW, P. W. (1991). Guinea pig alveolar macrophages kill Mycobacterium tuberculosis in vitro, but killing is independent of susceptibility to hydrogen peroxide or triggering of the respiratory burst. Microbial Pathogenesis 10, 199-207.

von Ossowski, I., Mulvey, M. R., Lero, P. A., Borys, A. \& LoeweN, P. C. (1991). Nucleotide sequence of Escherichia coli katE, which encodes catalase HPII. Journal of Bacteriology 173, 514-520.

PATel, B. K. R., BANerJeE, D. K. \& BUtCheR, P. P. (1991). Extraction and characterization of mRNA from mycobacteria: implication for virulence gene identification. Journal of Microbiological Methods 13, 99-111.
Rouse, D. A., Morris, S. L., Karpas, A. B., Mackall, J. C., Probst, P. G. \& CHAPARAS, S. D. (1991). Immunological characterization of recombinant antigens isolated from a Mycobacterium avium $\lambda \mathrm{gt} 11$ expression library by using monoclonal antibody probes. Infection and Immunity 59, 2595-2600.

SAMbrooK, J., FritsCh, E. \& MANiATIS, T. (1989). Molecular Cloning : a Laboratory Manual, 2nd edn. NY: Cold Spring Harbor, Cold Spring Harbor Press.

ShINNICK, T. M. (1987). The 65 kilodalton antigen of Mycobacterium tuberculosis. Journal of Bacteriology 169, 1080-1088.

Shinnick, T. M., Plikaytis, B. B., Hyche, A. D., Landingham, R. M. \& WALKER, L. L. (1989). The Mycobacterium tuberculosis BCG- $\alpha$ protein has homology to the Escherichia coli GroES protein. Nucleic Acids Research 17, 1254.

Stover, C. K., De la Cruz, V. F., Fuerst, T. R., Burlein, J. E., Benson, L. A., Bennett, L. T., Bansal, G. P., Young, J. E., Lee, M. H., Hatfull, G. F., SNapper, S. B., Barletta, R. G., Jacobs, W. R. \& BLoom, B. R. (1991). New use of BCG for recombinant vaccines. Nature, London 351, 456-460.

Tartaglia, T. A., Storz, G. \& Ames, B. N. (1989). Identification and molecular analysis of oxyR-regulated promoters important for the bacterial adaption to oxidative stress. Journal of Molecular Biology 210, 709-719.

Triggs-Raine, B. L., Dable, B. W., Mulvey, M. R., Sorlez, P. A. \& LOEWEN, P. C. (1988). Nucleotide sequence of katG, encoding catalase HPI of Escherichia coli. Journal of Bacteriology 170, 44154419.

W ALKER, L. \& LowRIE, D. B. (1981). Killing of Mycobacterium microti by immunologically activated macrophages. Nature, London 293, 69-70.

WAYNE, L. G. \& DiAZ, G. A. (1982). Serological, taxonomic and kinetic studies of the $\mathrm{T}$ and $\mathrm{M}$ classes of mycobacterial catalases. International Journal of Systematic Bacteriology 32, 296-304.

YounG, L. S. (1988). Mycobacterium avium complex infection. Journal of Infectious Diseases 157, 863-867.

Zhang, Y., Heym, B., Allen, B., Young, D. \& Cole, S. (1992). The catalase-peroxidase gene and isoniazid resistance of Mycobacterium tuberculosis. Nature, London 358, 591-593. 